top and bottom to allow the glasses and a wooden slide to be inserted; it is not necessary to have the grooves, but is more agreeable. In the centre of both sides of the box is cut a hole $1 \frac{1}{2} \mathrm{in}$. in diameter, the box being large-6 6 in. by $4 \frac{1}{2}$ in.--in order to shut out light from the side. I slide in, say, a red glass and a wooden slide having a diaphragm of $\frac{1}{1}$ in., and hold it up opposite an ordinary argand burner. The man to be examined stands four yards away. This now represents a signal lamp at a certain distance (vide table). By using wooden slides, with diaphragms of different sizes, I can estimate the man's vision for distance as well. Therefore, with a man four yards away, a light is seen through a diaphragm with

Diameter $1 \frac{1}{2}$ in. $\left\{\begin{array}{c}\text { representing an ordinary } \\ 6 \text {-in. railway signal }\end{array}\right\}$ at 16 yards.

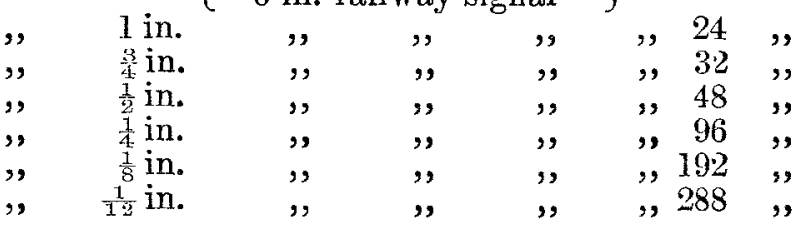

I represent the appearance of for by using a slide of ground glass, ground on one side only, increasing or diminishing the amount as the ground glass is in front of or behind the red. In actual practice I first use the $\frac{1}{12}$ in. diaphragm, and, as seen from the table, the light in this test is equal to an ordinary $6 \mathrm{in}$. railway lamp at 288 yardsa distance quite easy for any train to pull up in, and beyond any range of colour-blindness.

The Holmgren wools and the cavalry test I consider useless for two reasons: they are unscientific, and do not eliminate the possible factor of colour ignorance in the person examined.-I am, Sirs, yours faithfully,

Rotherham, Jan. 6th, 1890.

F. B. JUDGE BALDWIN.

\section{THE PROPOSED "PUBLIC MEDICAL SERVICE."} To the Editors of THE LANCET.

Sirs, - In reply to Dr. Carpenter, let me say that the report of the rneeting of the Metropolitan Branch of the British Medical Association, which appeared in the British Medical Journal of Dec. 21st, 1889, is substantially accurate, though brief. Mr. Carpenter rightly says that the resolution, which he represented to have been passed, was an amendment to Mr. Nelson Hardy's resolution. Mr. Nelson Hardy's resolution, in a much modified form, was undoubtedly passed; therefore no amendment other than such modification can have been passed.

$$
\text { I am, Sirs, yours faithfully, }
$$

HuGH WOODS, M.D.

* ${ }_{*}^{*}$ This correspondence must now cease. -ED. L.

\section{MEAN DURATION OF LIFE.}

\section{To the Editors of THE LANCET.}

SrRs,_Some discussion having arisen as to the method employed by me in estimating the mean duration of life in St. George's, Hanover-square, I wish to say that in 1876 and for several years subsequently $I$ stated in my annual reports that my calcnlations were based upon Dr. Bristowe's formula for calculating the mean duration of life from the birth-rates and death-rates, as explained in his paper read before the Society of Medical Officers of Health in 1876 , but for some years past I have not been in the habit of mentioning the formula by which the results were obtained. The formula is :-

$$
x=\frac{\log \cdot b-\log . d}{\log .\left(1+r_{.}\right)}
$$

Where $x=$ Mean duration of life.

$b=$ Birth-rate per unit of the population.

$d=$ Death-rate per unit of the population.

$r=$ Increase per unit of the population $=b-a$.

I never intended it to be inferred that I used the lifetable method, but always expressly stated that the numbers were calculated from the birth-rates and death-rates. I may add that the numbers so calculated are approximately the same as those obtained by the formula, in which the reciprocals of the birth-rates and death-rates are employed, and that the figure obtained for the mean duration of lite in the Mayfair subdistrict, which I quite admit is " pheno- menal," is owing to the combination of an abnormally low birth-rate with an exceptionally low death-rate; while the difference between the figures for the Mayfair and Belgravia. subdistricts, described as "incomprehensible," is easily explained by the fact that, while the deatl-rate of the latter is only 4 per 1000 higher than that of the former, its birth-rate is more than half as larce again. Of course I quite agree that neither of the above, nor any other simple formula, gives the correct mean duration of life obtained only by the life-table miethod. I am, Sirs, yours faithfully,

Savile-row, London, W., Jan. 8th, $1890 . \quad$ W. H. CORFIELD.

\section{THE INFLUENZA EPIDEMIC.}

THE real characteristic of the "Russian influenza "-viz., the rapidity of its dissemination among a population once it has gained a footing - has been fully exemplified in the metropolis during the past week. For whereas ten days ago we were noting only the occurrence of comparatively few cases, the numbers attacked since then have been extraordinarily high. The returns given below from various London hospitals furnish only a small part of the list of the sufferers, individuals in all classes of society, the employés of public institutions and large private establishments, business houses, \&c. Several barracks have been invaded. So far, fortunately, the type of the affection here has been comparatively mild and singularly uniform in its characters--sudden onset, muscular and orbital pains, pyrexia of two or three days' duration, followed or accompanied by catarrh, but in only a small proportion by the more serious complications of pleurisy and pneumonia. In several cases an erythematous rash has been observed. The attack, even in its milder forms, produces a disproportionate degree of physical and mental prostration, which retards convalescence. The presence of the epidemic is noted in all parts of the country-from Portsmouth and Plymouth in the south, to Cardiff in the west, and Edinburgh in the north. In Birmingham it is especially rife. It has also appeared in Dublin, and every day brings information of fresh centres in the provinces; and if it follow the same course as it has done on the Continent, we fear it will be some time before we hear the last of it in this country. Indeed, abroad it is reappearing in places from which it had almost disappeared--such as Copenhagen. It is at last abating in Paris as at Berlin, but it is spreading in Italy, Servia, and Greece. From New York the latest information is that the epidemic is decreasing there. A remarkable piece of intelligence respecting it, which has its parallel in the records. of earlier epidemics, is the account of its breaking out on board the Messageries Maritimes Company's steamer Alphéc, on the voyage from Constantinople to Marseilles. The whole of the passengers and the greater part of the crew were affected, only six men and the captain being available to work the vessel.

The following statements from the different hospitals throughout the metropolis indicate the severity, and progress of the malady up to Thursday, the 9th inst. :-

Westminster Hospital. - At this hospital about twenty fresh patients are treated daily, and an average of about the same number are seen in the out-patient department. The disease here is of a comparatively mild type, and the invasion gradual in the majority of cases, although in some cases the patient is prostrated in a few hours. Shiverinc is generally more or less present in the severer cases, and bronchial irritation is almost invariable. The temperature averages $102^{\circ}$, and varies from $101^{\circ}$ to $103^{\circ}$. Both sexes are attacked in equal proportion, and mostly between the ages of fifteen and forty years. Coryza does not seem common, but pains in the back and prostration, of ten so great as to render it difficult to foretell the period of perfect recovery, are the most unvarying features. The treatment here has 